\title{
Review: SSRIs and tricyclic antidepressants increase response rates in post-traumatic stress disorder in the short term
}

\author{
Stein DJ, Zungu-Dirwayi N, van Der Linden GJ, et al. Pharmacotherapy for posttraumatic stress disorder. Cochrane
} Database Syst Rev 2000;(4):CD002795 (latest version 20 Jul 2000).

\section{QUESTION: In patients with post-traumatic stress disorder (PTSD), is pharmacotherapy effective for relieving symptoms?}

\section{Data sources}

Studies were identified by searching Medline (1966-99); PsycLIT; the National PTSD Center Pilots database; Dissertation Abstracts; and the Cochrane Collaboration Depression, Anxiety \& Neurosis Controlled Trials Register; by scanning reference lists of articles; and by contacting researchers and pharmaceutical companies.

Source of funding: $M R C$ Research Unit on Anxiety and Stress Disorders, Cape Town, South Africa.

For correspondence: Professor DJ Stein, MRC Research Unit on Anxiety Disorders, University of Stellenbosch, PO Box 19063, Tygerberg 7505, Cape Town, South Africa. Fax +27 219335790.

\section{Study selection}

Published or unpublished randomised controlled trials (RCTs) in any language were selected if participants had PTSD (as defined by authors) and if a drug was compared with placebo or another drug.

\section{Data extraction}

2 reviewers independently extracted data on participant characteristics; presence of comorbid depression; drug regimens; outcome measures; type of data analysis; dropout rates; and methodological quality. Response was defined as a "much" or "very much improved" rating on the Clinical Global Impressions scale change item or an equivalent measure.

\section{Main results}

13 RCTs (14 comparisons) of tricyclic antidepressants (TCAs) (3 comparisons), monoamine oxidase (MAO) inhibitors (2 comparisons), brofaromine (2 comparisons), selective serotonin reuptake inhibitors (SSRIs) (4 comparisons), alprazolam (1 comparison), lamotrigine (1 comparison), and inositol (1 comparison) met criteria. Follow up ranged from 4-14 weeks (mean 9 wks). More patients responded to SSRIs or TCAs than placebo (table). In 1 RCT, phenelzine led to a higher response rate than placebo; 1 small RCT of lamotrigine and 2 RCTs of brofaromine showed no difference in response rates between groups (table).

\section{Conclusions}

In patients with post-traumatic stress disorder, selective serotonin reuptake inhibitors and tricyclic antidepressants increase response rates. Preliminary evidence shows a benefit for phenelzine but not brofaromine.

Pharmacotherapy v placebo for post-traumatic stress disorder (PTSD)*

\begin{tabular}{|c|c|c|c|c|c|c|}
\hline \multirow[b]{2}{*}{ Outcome at mean 9 weeks } & \multirow[b]{2}{*}{ Number of studies } & \multirow[b]{2}{*}{ Drugs } & \multicolumn{2}{|c|}{ Weighted event rates } & \multirow[b]{2}{*}{ RBI $(95 \%$ CI) } & \multirow[b]{2}{*}{ NNT (CI) } \\
\hline & & & Pharmacotherapy & Placebo & & \\
\hline \multirow[t]{5}{*}{$\begin{array}{l}\text { Response rate (much or very much } \\
\text { improved on CGI change item) }\end{array}$} & $4(n=151)$ & SSRIs & $54 \%$ & $38 \%$ & $40 \%$ (18 to 67$)$ & 7 (5 to 12 ) \\
\hline & $2(n=81)$ & TCAs & $70 \%$ & $40 \%$ & $66 \%$ (8 to 155$)$ & $4(2$ to 11$)$ \\
\hline & $2(n=178)$ & Brofaromine & $66 \%$ & $55 \%$ & $19 \%(-16$ to 68$)$ & Not significant \\
\hline & $1(n=14)$ & Lamotrigine & $50 \% \dagger$ & $25 \% \dagger$ & $100 \%(-49$ to 1069$)$ & Not significant \\
\hline & $1(n=37)$ & Phenelzine & $68 \% \dagger$ & $28 \% \dagger$ & $146 \%$ (19 to 471$)$ & $3(2$ to 13$)$ \\
\hline
\end{tabular}

${ }^{*} \mathrm{CGI}=\mathrm{Clinical}$ Global Impressions scale; SSRIs=selective serotonin reuptake inhibitors; TCAs=tricyclic antidepressants. Other abbreviations defined in glossary; weighted event rates, RBI, NNT, and $\mathrm{Cl}$ calculated from data in article.

†Not weighted.

\section{COMMENTARY}

In the past decade, there has been a rapid growth of research into the neurobiology of PTSD and a corresponding increase in interest in pharmacological treatments. This excellent systematic review by Stein $e t$ al investigates the efficacy of such interventions.

At first sight, asking whether pharmacotherapy is effective in PTSD may not appear the most helpful of questions; a clinician must, after all, prescribe a particular drug. Although psychotropic drugs of every class have been studied in patients with PTSD, most studies have been small, non-randomised, and open label. Among RCTs, only trials of antidepressants and lamotrigine yielded data suitable for the meta-analysis. High dropout rates were a problem for almost all RCTs.

Given the state of the evidence base, recommendations about specific pharmacotherapeutic strategies are necessarily preliminary.

The review finds consistent evidence of global improvement in patients treated with SSRIs. These are the largest and best quality RCTs and justifiably form the basis for recent expert statements recommending SSRIs as first line drug treatment for PTSD. ${ }^{1}$ RCTs of tricyclic antidepressants also show benefit, but the trials are smaller and constitute poorer evidence. A good quality, large trial of a well tolerated TCA is clearly needed. The MAO inhibitor phenelzine showed benefit in 1 small study, but is unlikely to find a place as first line treatment. Few studies provided dimensional symptom data suitable for the analysis, but there was some evidence of an effect on core symptoms of PTSD, not just on associated mood disturbance.

Comorbidity is common in PTSD. The evidence in favour of SSRIs is supported in patients with comorbid major depression, who were included in substantial numbers in the larger trials. Unfortunately, no light is shed on the difficult problem of managing patients with comorbid substance use disorders.

Pharmacotherapy is clearly a viable alternative (or complement) to psychotherapy for patients with PTSD, but we remain some way from being able to answer specific clinical questions about its optimal use.

Jenny M McCleery, MA, MB, MRCPsych University of Oxford Oxford, $U K$

1 Ballenger JC, Davidson JR, Lecrubier Y, et al. Consensus statement on post traumatic stress disorder from the international consensus group on depression and anxiety.J Clin Psychiatry 2000;61:60-6. 